Article

\title{
Hyperspectral Characteristics of Oil Sand, Part 1: Prediction of Processability and Froth Quality from Measurements of Ore
}

\author{
Benoit Rivard ${ }^{1, *}$, Jilu Feng ${ }^{1}$, Derek Russell ${ }^{2} \mathbb{C}$, Vivek Bhushan ${ }^{3}$ and Michael Lipsett ${ }^{4}$ \\ 1 Department of Earth and Atmospheric Sciences, University of Alberta, Edmonton, AB T6G 2E3, Canada; \\ jfeng@ualberta.ca \\ 2 Department of Chemical Engineering, Queen's University, Kingston, ON K7L 3N6, Canada; \\ 18dar@queensu.ca \\ 3 Enbridge Inc., Calgary, AB T2P 3L8, Canada; vivek.bhushan@enbridge.com \\ 4 Department of Mechanical Engineering, University of Alberta, Edmonton, AB T6G 1H9, Canada; \\ mlipsett@ualberta.ca \\ * Correspondence: benoit.rivard@ualberta.ca
}

Received: 13 October 2020; Accepted: 1 December 2020; Published: 18 December 2020

\begin{abstract}
This study is the first of two companion papers using hyperspectral data to generate predictive models of oil sand ore and froth characteristics as a potential new means for process control. In Alberta, Canada, shallow oil sands deposits are accessed by surface mining and crushed ore is transported to a processing plant for extraction of bitumen using flotation processes. The ore displays considerable variability in clay, bitumen, and fines which affects their behavior in flotation units. Using oil sand ore spanning a range of bitumen and fines characteristics, flotation experiments were performed to generate froth in a batch extractor to determine ore processability (e.g., separation performance) and froth characteristics (color, bitumen, solids). From hyperspectral observations of ore, models can predict the \%bitumen content and $\%$ fines (particle passing at 44 and $3.9 \mu \mathrm{m})$ of ore but the models with highest $\mathrm{r}^{2}(>0.96)$ predict the solids/bitumen of froth and the processability of ore. Spectral observations collected on ore upstream of the separation vessels could therefore offer a first order assessment of froth quality for an ore blend before the ore enters the plant. These models could also potentially be used to monitor and control the performance of the blending process as another means to control the performance of the flotation process.
\end{abstract}

Keywords: oil sands processing; bitumen extraction; hyperspectral; infrared; froth; processability; ore; mining; flotation

\section{Introduction}

Oil sands are comprised of bitumen, solid particles, and water [1-3]. In Alberta, Canada, shallow oil sands deposits are accessed by surface mining and crushed ore is transported to a processing plant for extraction of aerated bitumen from water and oil sands slurry using flotation processes $[2,4,5]$. The Clark hot water extraction process, which involves conditioning, multistage separation, and froth treatment, is the common method for extracting bitumen from the oil sands and water slurry $[3,6]$. The conditioning stage allows the oil sand matrix to disintegrate, releasing bitumen into the water phase, where bitumen droplets coalescence and bitumen-air attachment occurs in favorable interfacial conditions. The aerated slurry enters a separation unit where bitumen floats to the top of the separation unit in the froth layer. The underflow stream contains waste materials including solid particles. The middling layer is transferred to secondary units (often entailing mechanical flotation) for recovery 
of more bitumen. The froth from the primary and secondary flotation separation units are combined and undergo treatment to remove water and solids prior to the bitumen upgrading process. Tailings from the primary and secondary separation units are transported to settling basins for eventual reclamation.

Effective flotation process control depends on both hydrodynamic conditions and interfacial conditions. The ore deposits are not homogeneous and the ore displays considerable variability in clay, bitumen, and fines $[1,7]$. Thus, oil sand ores have a range of mineral contents, which affects their behavior in flotation units. The current strategy for achieving a good process performance is to blend the ore and then run the process at a fairly high temperature. These strategies improve the process robustness, but they are not sufficient to ensure a good separation performance. For this reason, improved observability of the ore characteristics and the flotation process kinetics would be a valuable tool to evaluate the process performance.

The optical properties of the ore provide one means of determining ore characteristics. Reflectance and adsorption of light can reveal information about mineralogy, particle size, and bitumen content [8-12]. Near infrared sensors have been used for over twenty years to estimate the bitumen content of oil sands ore based on two spectral bands [8]. This technique has been extended to a large number of bands using modern instruments, which allows for more robust estimation methods that do not need to be tuned for particular ore bodies [11,12]. If spatial relationships are important in addition to individual spectral points, then hyperspectral images can be collected using spectral cameras. These methods are in current use for the estimation of bitumen in oil sand drill core [13-16] and have been used for imaging of oil sands outcrops and mine walls [17].

This study is the first of two companion papers using hyperspectral data to generate predictive models of ore and froth characteristics as a potential new means for process control. Both studies make use of flotation experiments performed on a laboratory scale to generate froth in a batch extractor. The flotation process involves conditioning and aeration of the slurry mixture using an impeller; as a result, bitumen and bubbles are transferred to the froth. In this study, we report observations of the froth color captured during the flotation process for qualitative analysis. The study then examines the relationships between properties of oil sands ore (bitumen, fines, reflectance) and oil sands froth (color, bitumen, solids) produced under standard batch separation conditions, along with ore processability - that is, the separation performance. Processability and recovery are terms used interchangeably in oil sands. The flotation experiments make use of a suite of samples with a range of processabilities. The aim of the current study is to use the reflectance spectra of oil sands ore to generate predictive models of ore characteristics (bitumen and fines) and processability, froth color (as a qualitative metric of froth quality), and froth solids to bitumen content (as a quantitative metric). These models would then enable assessment of the flotation performance based on hyperspectral observations of the incoming feedstock in real time in a mine. We discuss the potential use of these findings for control of the flotation process. In our follow-up companion paper, focus is given to hyperspectral observations of the froth and their use to generate predictive models of froth characteristics with a focus on fines and ultrafines. Together, these studies capture observations of the ore and resulting froth offering new predictive capabilities based on hyperspectral data and a vision for their potential use in ore sorting and flotation process control.

\section{Materials}

Two sample suites were used in this study - the first to establish predictive models of ore characteristics and the second to conduct the flotation experiments.

The first suite encompasses 136 samples collected by mine geologists from various mines of the Athabasca oil sands of Alberta, Canada. These samples were collected early in the study from a variety of mine locations (from different mine faces) during routine mining operations and were stored at a temperature of $-20{ }^{\circ} \mathrm{C}$ to prevent loss of water and aromatic components. Dean Stark analyses [18] were conducted on each sample to measure the weight percent of bitumen, water, solids, and the fines content below 44 (pp44 measured as percent passing at $44 \mu \mathrm{m}$ particle size) and $3.9 \mu \mathrm{m}$ (pp3.9) was 
also determined. The total bitumen content (TBC) ranged from $0.7 \%$ to $16 \%$ with water content varying from $0.5 \%$ to $14 \%$. The samples were divided into a modeling suite to establish predictive models of ore characteristics (TBC, pp44, pp3.9), and a validation suite to evaluate the models. The modeling suite (85 samples for TBC and pp44, 42 samples for pp3.9) was taken from one mine and validation samples are from a separate mine (51 samples). Using samples from different mines for modeling and validation served as a natural division of the data for the analysis and provided a test of the general applicability of the derived models. The distribution of the bitumen content was fairly uniform for the model suite but clustered into two weight percentage groupings for the validation suite (at $7 \%$ and $15 \%$ ).

The second sample suite was obtained later in the study and used to conduct the flotation experiment and consisted of an additional ten samples selected by mine geologists at a number of oil sand mines in Alberta with the expectation that the samples would span a range of processability values. These samples represent a range of depositional environments (fluvial, estuarine, and marine) (Table 1). Prior to the flotation experiment, the samples were allowed to equilibrate to room temperature and each sample was crushed with a comil and homogenized. Four subsamples were generated $(300 \mathrm{~g}$ each) for the flotation test. Dean Stark analyses were conducted on an additional $300 \mathrm{~g}$ subset of each sample (Table 1). The TBC for these ten samples spans $7.06-14.85 \%$ ( $\leq 0.5 \%$ analytical error) and the fines content spans $2.44-46.24 \%$ (pp44) and $2.11-16.00 \%$ (pp3.9). The samples cover a range of bitumen and fines contents and thus should have variability in processability.

Table 1. Characteristics of the ten oil sands samples used for the flotation experiment.

\begin{tabular}{|c|c|c|c|c|c|c|}
\hline Sample ID & \%Bitumen & $\%$ Water & \%Solids & *pp44 & ${ }^{*}$ pp3.9 & Field Description \\
\hline Sp\#1 & 8.35 & 5.39 & 86.05 & 31.00 & 15.19 & $\begin{array}{l}\text { Average } \\
\text { (mixed ore) }\end{array}$ \\
\hline Sp\#2 & 14.83 & 2.58 & 83.27 & 11.13 & 4.17 & Marine \\
\hline Sp\#3 & 9.82 & 4.46 & 83.52 & 27.30 & 9.63 & $\begin{array}{l}\text { High grade-med fines Marine } \\
\text { (bedded) }\end{array}$ \\
\hline Sp\#4 & 7.81 & 6.72 & 85.88 & 40.06 & 13.51 & $\begin{array}{c}\text { Low grade-high fines Estuarine } \\
\text { (bedded) }\end{array}$ \\
\hline Sp\#5 & 9.45 & 6.84 & 83.42 & 40.75 & 13.72 & $\begin{array}{l}\text { Med grade-high fines Marine } \\
\text { (bedded) }\end{array}$ \\
\hline Sp\#6 & 7.06 & 3.53 & 89.21 & 46.24 & 16.00 & $\begin{array}{l}\text { Average } \\
\text { (mixed ore) }\end{array}$ \\
\hline Sp\#7 & 11.63 & 3.36 & 84.70 & 6.71 & 3.37 & High grade-low fines Marine \\
\hline Sp\#8 & 8.02 & 7.78 & 84.42 & 24.98 & 8.92 & $\begin{array}{l}\text { Low grade-med fines Fluvial } \\
\text { (burrowed) }\end{array}$ \\
\hline Sp\#9 & 13.97 & 3.59 & 82.26 & 13.83 & 5.53 & High grade-low fines Estuarine \\
\hline Sp\#10 & 14.20 & 3.12 & 83.16 & 2.44 & 2.11 & Marine \\
\hline
\end{tabular}

\section{Methods}

\subsection{Flotation Experiments}

Laboratory-scale batch flotation recovery tests in oil sands have developed along two general lines. One approach has been to develop custom flotation units for batch conditioning, aeration, and flotation studies. For example, the Syncrude Batch Extraction Unit (BEU) is a small deep flotation cell that promotes a fairly thick aerated bitumen froth supernatant layer. The other approach has been to take standard apparatus and then modify the experimental conditions. Many researchers have used commercial Denver cells with varying ratios of oil sand to water plus reagents. The Masliyah group at the University of Alberta has reported results using ratios of $300 \mathrm{~g}$ oil sand to $800 \mathrm{~g}$ water in a $2 \mathrm{~L}$ cell [19], and $130 \mathrm{~g}$ oil sand to $400 \mathrm{~g}$ water in a $1 \mathrm{~L}$ cell [20] before amending the procedure from 300 to $950 \mathrm{~g}$ water, which is the ratio used in the present study.

Flotation experiments were conducted using a $2 \mathrm{~L}$ Metso Denver flotation cell (Figure 1). Three-hundred grams of homogenized oil sand was mixed with $950 \mathrm{ml}$ of untreated tap water. Air bubbles were injected 
(aeration) into the slurry agitated by an impeller. The speed of the impeller was set to 1200 and $1800 \mathrm{rpm}$ while the aeration rate was 100 and $200 \mathrm{~mL} / \mathrm{min}$ at each impeller speed resulting in four operating conditions, each of which produced froth for a given sample. The temperature of the slurry was maintained at forty-five degrees Celsius. The choice of this controlled variable is based on the industry trend of lower extraction temperature, as implemented at several mines.

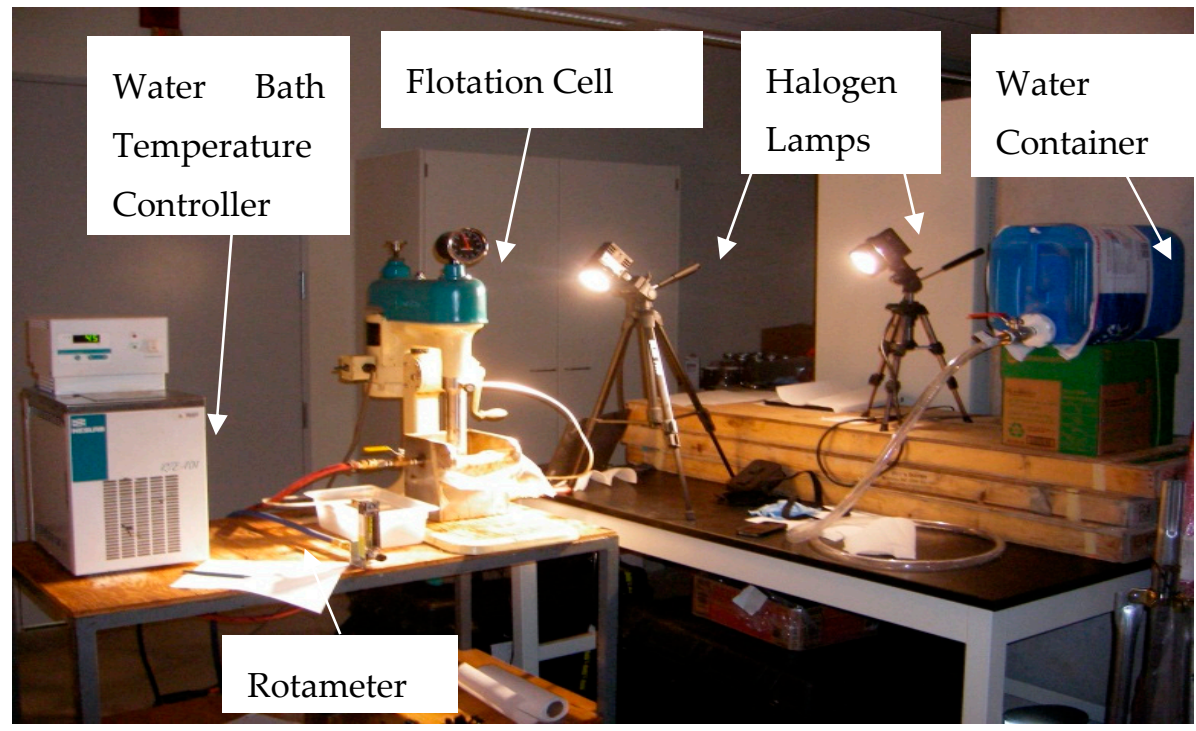

Figure 1. Flotation experimental apparatus.

In a continuous aeration/agitation process, the first $5 \mathrm{~min}$ of the run time was the conditioning stage and froth was collected during the following $10 \mathrm{~min}$. A paddle was used to remove froth manually rather than allowing overflow from the cell. The froth (Figure 2, photos B1-B3) was stored in a glass jar (Figure 2, photos C1-C3) for further analysis. The froth samples generated for the four operating conditions (a total of 40 froths for 10 ore samples) underwent Dean Stark analysis to determine their mass content of bitumen, water, and solids. For each of the 10 samples, the mass bitumen content from the four operating conditions were averaged as a representation of the total bitumen extractable (TBE).

Qualitative observations of froth color, structure, and morphology were collected during the flotation experiment. These qualitative observations as well as quantitative indices were derived to describe froth quality and ore processability. They were later used to examine their relation to features in spectra of ore with the aim of developing predictive models. The color of froth was assessed in the flotation vessel as well as any structure observed and amount of fines settled at the bottom of the glass jar (Figure 2 photos C1-C3) once the froth was extracted. The weight percentage (over the total froth mass) of bitumen, solids, and the solids/bitumen ratio in the froth were determined as quantitative indicators of froth quality. The ore processability of each sample was then determined as the ratio of TBE to TBC. These indices were determined from averaged data for each sample for the four flotation conditions.

\subsection{Acquisition of Reflectance Spectra}

Spectral measurements of homogenized ore were conducted using a Panalytical FieldSpec FR portable spectrometer (Malvern Panalytical). Prior to spectral measurements, the samples were allowed to equilibrate to room temperature. The instrument, positioned with a nadir view of the sample, collected visible and near infrared (VNIR, 0.35-2.50 $\mu \mathrm{m}, 2151$ bands) spectral reflectance using a tripod mounted $50 \mathrm{~W}$ quartz-halogen light source positioned at a $30^{\circ}$ incident angle. The footprint of the sample viewed by the instrument was $2 \mathrm{~cm}$ in diameter and a spectrum was collected from six different footprints $5 \mathrm{~cm}$ apart on each sample. The spectrum of each footprint was collected within a second and 
consisted of the average of 25 co-adds to minimize signal noise. Each sample spectrum was normalized to that of a Spectralon ${ }^{\mathrm{TM}}$ panel (99\% reflectance, Labsphere Inc.) to obtain a reflectance spectrum.

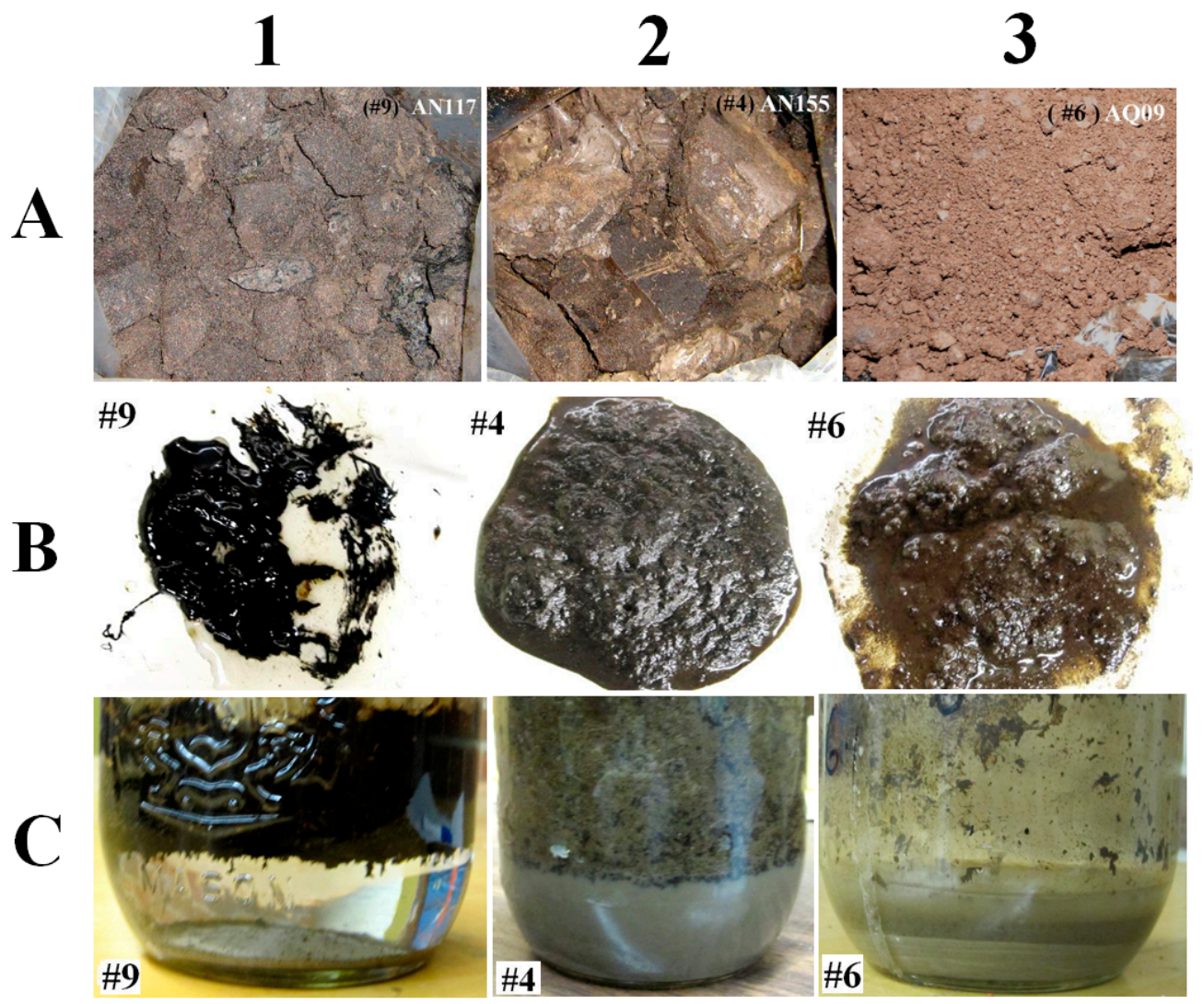

Figure 2. Photos of three oil sand ores in row (A) $(\mathrm{Sp \# 4}, 6,9)$, the resulting froth in row (B), and segregation once stored in jar as shown in row $(\mathbf{C})$.

\subsection{Data Analysis}

The acquisition of reflectance spectra from homogenized ore resulted in six spectra per sample which were averaged to generate a representative spectrum. Wavelet analysis was then applied to the spectra of all samples to minimize spectral noise and determine the spectral features most sensitive to froth quality and ore characteristics and processability. The latter were then used to develop predictive models.

\subsubsection{Spectral Processing with Wavelet Analysis}

The merits of analyzing hyperspectral data in the wavelet domain have been discussed in several studies [21-28]. As spectral data exhibit non-stationarity, that is, spectral signals that can vary both in amplitude (e.g., feature depth) and scale (e.g., feature width), reflectance spectra may be represented and decomposed as a sum of similar wave-like functions (wavelets), each capturing spectral information at a different scale (e.g., from high frequency noise to broad variations in the shape of the continuum). In past geological studies $[28,29]$, we demonstrated the use of a continuous wavelet transform (CWT) to minimize noise and intraclass variability seen in spectra of powdered minerals and to improve the discrimination of minerals. This technique was also used to improve the detection of bitumen and clay features (location, strength, and width) in oil sand spectra [11] by minimizing the influence of non-compositional effects, including variability in illumination due to sample micro-topography, which predominantly impact the amplitude of the spectral continuum. For this study, CWT analysis was used to preprocess the spectra for the selection of spectral features that best correlate with a given sample metric (e.g., processability). Each spectrum was transformed into ten wavelet scales with 
low-scale spectra best capturing mineral/bitumen features and high-scale spectra capturing the overall continuum of the reflectance spectrum [28].

To determine the spectral features sensitive to ore characteristics and processability and froth quality (color and solids/bitumen), we examined the correlation coefficient between the wavelet power, at each of the 2151 wavelengths and ten scales, with a known metric (e.g., processability) for the data of the entire sample suite. The resulting correlation coefficient (Rfeature) at each wavelength and scale can be visualized with the use of a scaleogram (Figure 3) which conveys the amplitude of the correlation coefficient in grey tones. The wavelet feature regions that are most strongly correlated or anti-correlated with a given metric can be highlighted by contours to identify the locations and width of features with highest correlation. These features were then used for the development of a predictive model of the metric.

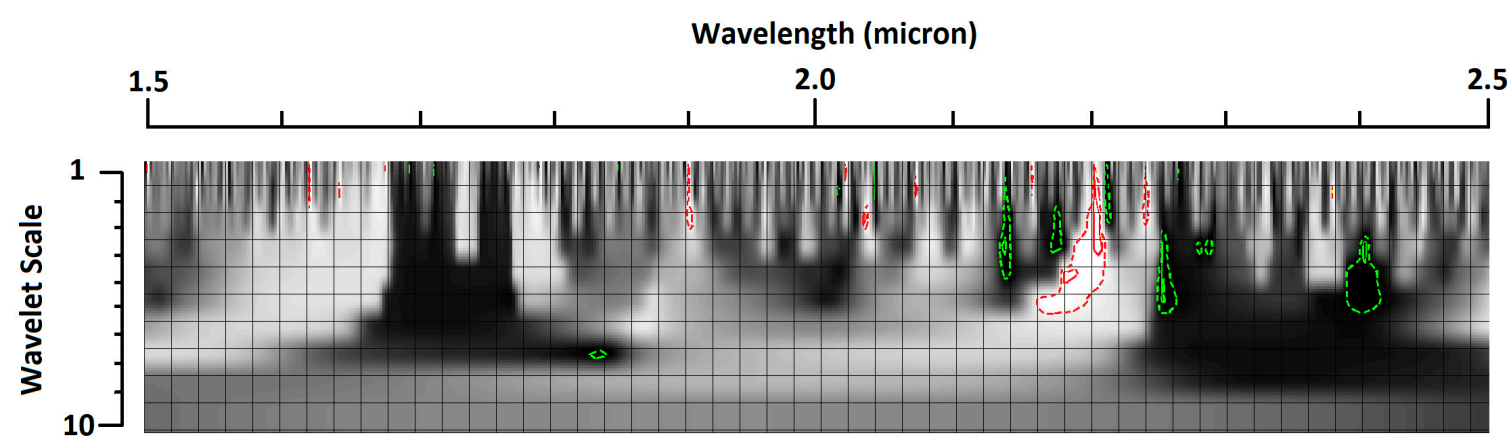

Figure 3. Scaleogram of the correlation coefficient Rfeature between ore processability and wavelet power for the 1.5 2.5 $\mu \mathrm{m}$ range. Red contours: Rfeature $=0.80$ and 0.85; Green contours: Rfeature $=$ -0.80 and -0.85 .

\subsubsection{Prediction of Ore Characteristics and Processability and Froth Solids/Bitumen}

The scaleogram of the correlation coefficient enables the selection of features most sensitive to a given sample metric. Their position and width were examined and compared to that of mineral, water, and bitumen features to label the selected spectral features. From these, six features of highest correlation were used for predictive modeling of ore characteristics, using a multiple regression technique. Three and four features were used for predictive modeling of ore processability and froth solids/bitumen, respectively.

\subsubsection{Prediction of Froth Color}

For froth color, the scaleogram was developed based on the correlation between wavelet power spectra and qualitative categorical data representing two color classes. Once features were identified from the scaleogram of the correlation coefficient, a froth color predictor/classifier was derived using 3 features as inputs in a multiple regression technique.

\section{Results}

\subsection{Froth Characteristics}

Froth demonstrated various color and bubble concentrations (from dark to brown; see Figure 2, photos B1-B3) in the separation vessel. Once froth was separated and stored in a glass container (Figure 2, photos C1-C3), three layers developed because of the sufficiently large density difference between the three components of the froth (solids, water, and bitumen). Solids in some samples (e.g., Sp\#4, Sp\#5, and Sp\#6) had a very slow settling rate and the water layer remained muddy after several hours and much of the solids remained agglomerated with the floating bitumen in an emulsified state resulting in a brown froth color (Figure 2, Sp\#4 and Sp\#6). However, froths of some samples (e.g., Sp\#7, Sp\#9, and Sp\#10) were dark with few solids visible in the froth and the water layer was 
clear (Figure 2, Sp\#9). For each sample, froth color was carefully recorded (Table 2). For simplicity and the purpose of classification, samples which produced dark and very dark froth $($ Sp\#2, 7, 8, 9, 10) were then assigned a category ID for dark froth (ID $=0$ ) and the samples which generated brown and very brown froth (Sp\#1, 3, 4, 5, 6) were assigned a category ID for brown (ID =1). There was an equal split of samples with dark and brown froths.

Table 2. Observed and measured froth characteristics.

\begin{tabular}{ccccccc}
\hline \multirow{2}{*}{ Sample ID } & \multirow{2}{*}{ Froth Color } & Color ID & \multicolumn{4}{c}{ Average Froth Quality } \\
\cline { 4 - 6 } & & & \%Bitumen & \%Solids & Solids/Bitumen & Processability \\
\hline Sp\#1 & Brown & 1 & 5.63 & 11.51 & 2.14 & 0.59 \\
Sp\#2 & Very Dark & 0 & 14.44 & 15.93 & 1.17 & 0.86 \\
Sp\#3 & Very Brown & 1 & 6.27 & 15.91 & 2.59 & 0.69 \\
Sp\#4 & Brown & 1 & 6.11 & 14.42 & 2.64 & 0.61 \\
Sp\#5 & Very Brown & 1 & 8.63 & 17.67 & 2.10 & 0.80 \\
Sp\#6 & Light Brown & 1 & 2.54 & 15.72 & 6.63 & 0.28 \\
Sp\#7 & Very Dark & 0 & 21.52 & 8.26 & 0.49 & 0.69 \\
Sp\#8 & Dark & 0 & 10.02 & 17.42 & 1.79 & 0.75 \\
Sp\#9 & Very Dark & 0 & 17.65 & 16.44 & 1.03 & 0.81 \\
Sp\#10 & Very Dark & 0 & 28.96 & 17.32 & 0.61 & 0.90 \\
\hline
\end{tabular}

${ }^{\text {a }}$ Froth data averaged over the 4 operating conditions.

The froth \%bitumen and \%solids characteristics (Table 2) reveal that all samples with dark froth displayed a higher \%bitumen in froth, the lowest \%bitumen being $10.02 \%$ for a dark froth. There was no clear link between froth color and \%solids in froth, both dark (8.26-17.42\%) and brown (11.51-17.67\%) froth displaying a range of \%solids. However, both froth populations were distinct in their solids/bitumen ratio (dark $<1.79$, brown $>2.1$ ). Froth color thus appears to be primarily a function of the \%bitumen in the froth which impacts the solids/bitumen ratio.

The flotation experiments enabled the estimation of sample processability for each of the four experimental conditions from which an averaged value is reported. Most samples showed consistent processability results across at least three of the four conditions (Figure 4). With the exception of sample \#5 (average processability of 0.8, Figure 4, Table 2), all samples with brown froths had a lower processability than samples that yielded a dark froth, suggesting a broad relationship between froth color and sample processability. The lowest processability for a sample with a dark froth was 0.69.

\subsection{Relationship between Froth Quality and Ore Characteristics}

Bitumen in ore (TBC) appears to be inversely correlated with pp44 and the two classes of froth color relate to these ore properties (Figure 5). All dark froths were generated from ore samples with lower fines contents regardless of the flotation condition (Figure 5). The ore sample of highest fines content that produced a dark froth had a pp44 of 24.98\% (Table 1, Sp\#8). All brown froths resulted from ore samples with a higher fines content (Table 1, 27.30-46.24\%). Four of the dark froth samples came from ores with highest TBC but one sample (Sp\#8) had lower TBC (8.02\%) than several samples that yielded a brown froth; thus, the froth classes could not be distinguished on the basis of TBC. Figure 6 helps to visualize the links between ore properties (TBC, pp44) and froth properties (color, \%bitumen, solids/bitumen). All dark froth samples have higher \%bitumen and lower solid/bitumen; they generally come from ores with higher TBC (4 of 5 samples, exception Sp\#8 a low-grade fluvial sediment) and they all come from ores with lower pp44. Although no direct link was observed between color and \%solids in froth, froth color appears be an indicator of fines content in ores and the propensity of ores with a lower fine content to generate a froth with higher \%bitumen and lower solids/bitumen ratio. 


\subsection{Relationship between Processability and Froth Characteristics}

The ore processability generally correlates to the solids/bitumen ratio and \%bitumen in froth (Figure 7) with ore of higher TBC (and lower fines) generally resulting in higher processability and in froth of higher \%bitumen and lower solids/bitumen. These observations are consistent with those described in the prior section when comparing ore properties (TBC, fines) to froth properties (\%bitumen and solids/bitumen) (Figure 6). However, links of ore processability to froth color are not as clear. Whereas the two froth classes could be clearly discerned on the basis of the fines content of the ore (Figure 6), no such clear distinction could be made on the basis of processability of the ore (Figure 7) for our limited sample suite, though a general trend of higher processability is observed for samples generating dark froths. This suggests that processability may be distinct from froth color as an indicator of bitumen recovery. A notable exception to the observed general trend is sample Sp\#7, a high-grade marine deposit $(\mathrm{TBC}=11.63 \%)$ with low fines (pp44 $=6.71 \%)$ but of lowest processability amongst samples that yielded a dark froth. This sample may differ in its clay mineral characteristics though this was not investigated in this study.
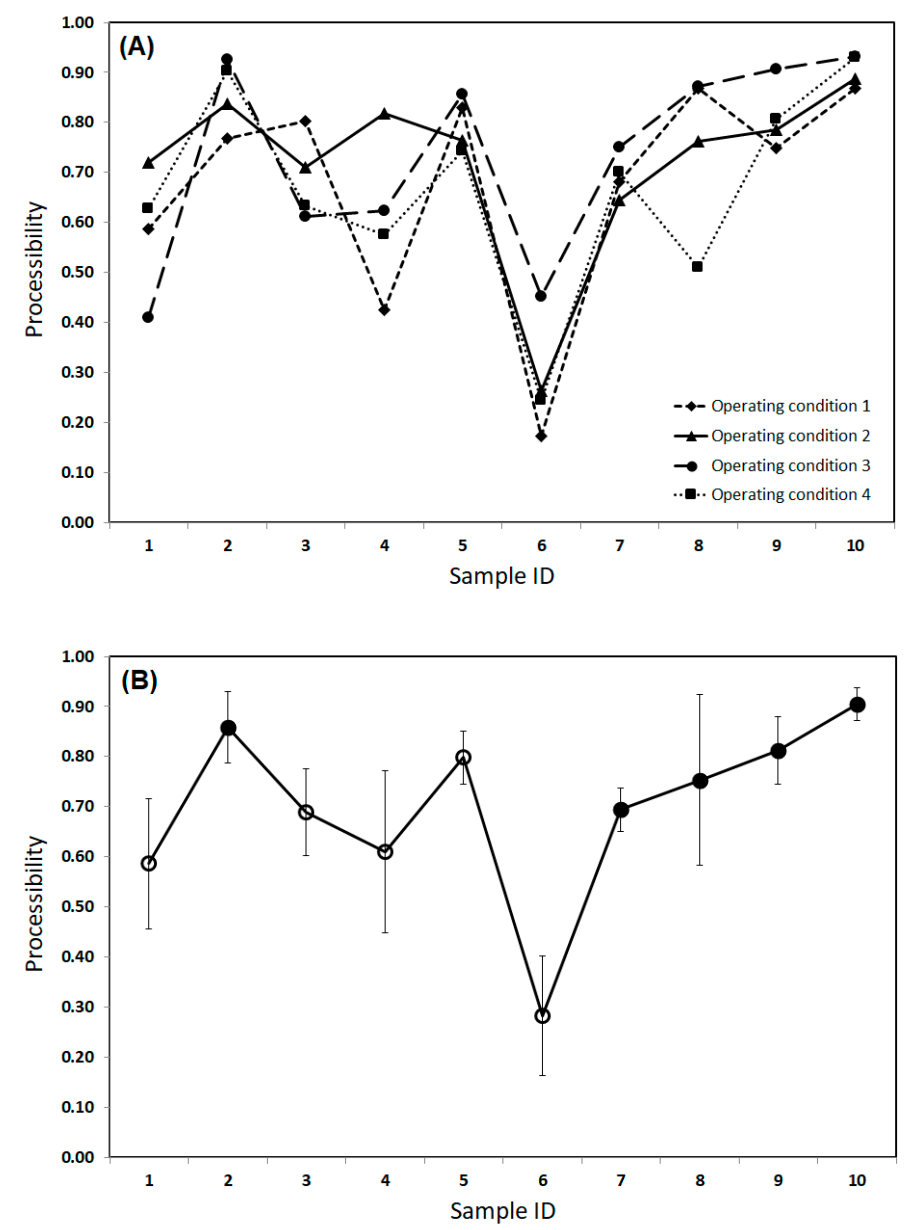

Figure 4. Processability for the ten samples. (A) measured for each of the four operating conditions. (B): averaged value for each sample based on the four operating conditions; open and filled circles for brown and dark froths, respectively. 


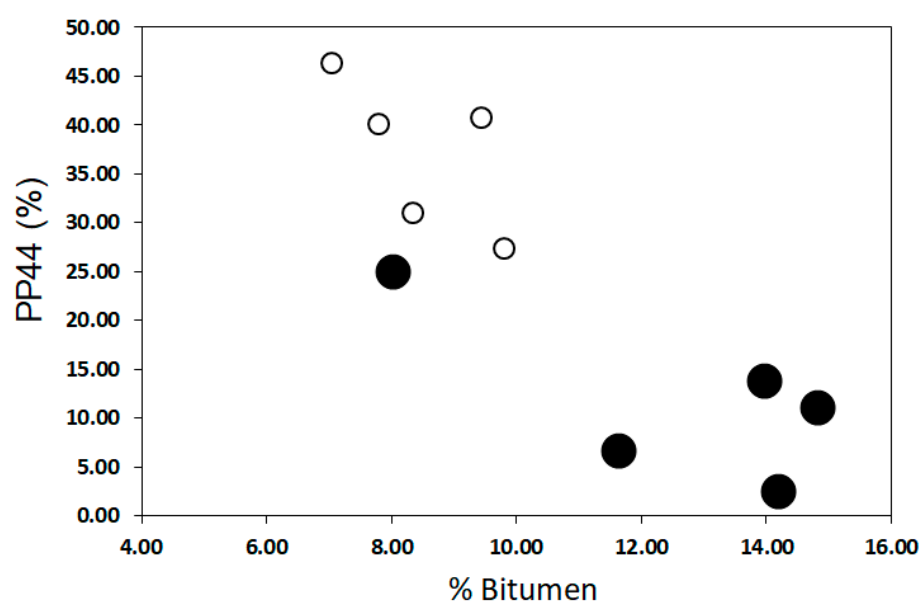

Figure 5. Froth color as a qualitative metric in relation to \%bitumen ( $x$ axis) and pp44 ( $y$ axis) in ore. Black and larger circles $=$ dark froths. Smaller circles $=$ brown froths.
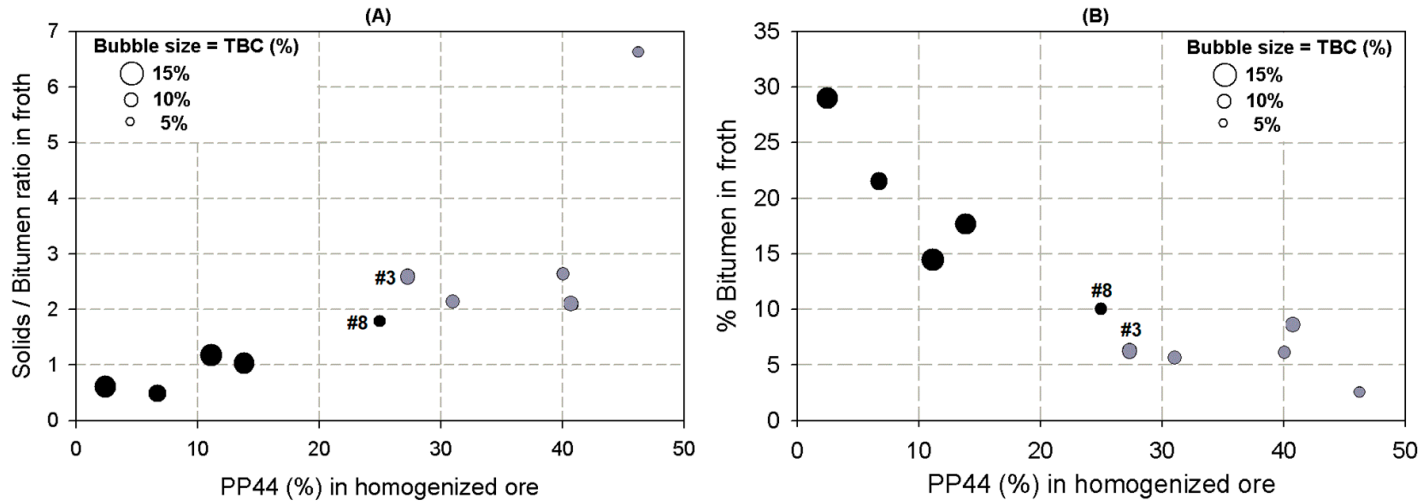

Figure 6. Scatterplots of solids/bitumen ratio and \%bitumen in froth versus pp44 (\%) in ore (A,B). Black circles $=$ samples with dark froth; grey circles $=$ samples with brown froth. Bubble size relates to percentage of total bitumen content (\%TBC).
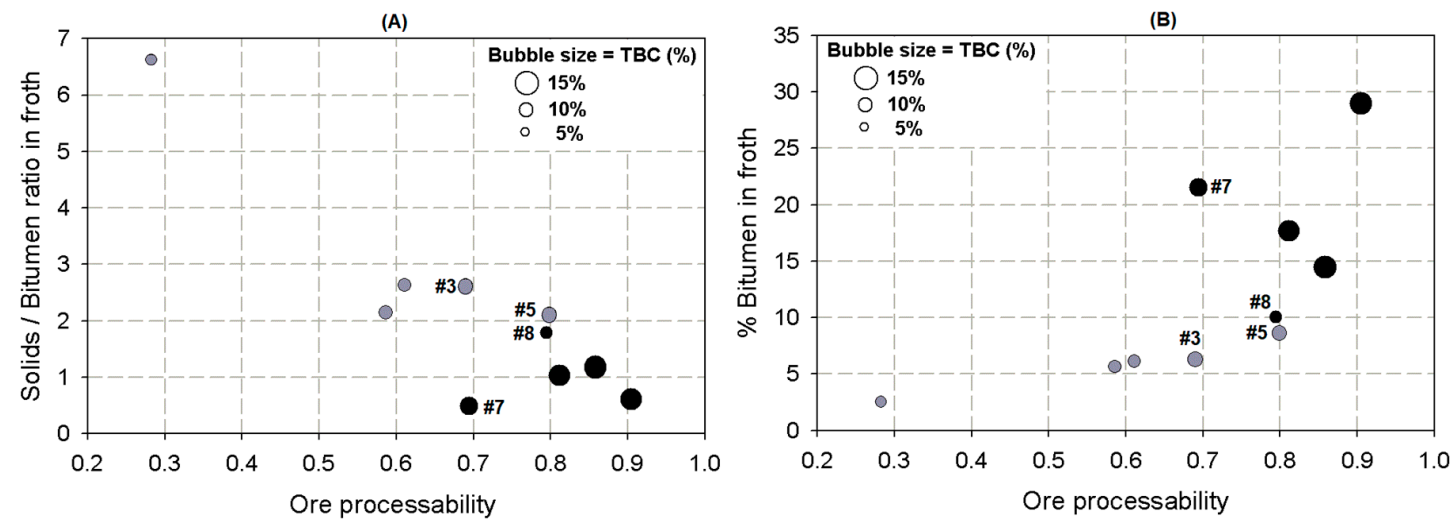

Figure 7. Scatterplots of solids/bitumen ratio and \%bitumen in froth versus processability (A,B). Black circles = samples with dark froth; grey circles = samples with brown froth. Bubble size relates to $\%$ TBC. 


\subsection{Spectral Characteristics of Ore}

All spectra collected from the homogenized ore samples used for the flotation experiments show little variability across the six measured locations for a given sample (standard deviation $<0.5 \%$ ). These are therefore well suited for correlation analysis with sample analysis toward predictive modeling. Spectra collected prior to sample homogenization display more variability (Figure 8 ) and are used here to showcase type absorption features seen in spectra of oil sands. Samples with higher fines tend to show greater compositional, and thus spectral, heterogeneity. The largest spectral variability was observed for Sp\#5 (Figure 8), a bedded marine deposit with $40.75 \%$ fines and the sample with highest fines. The standard deviation about the mean reflectance exceeds $15 \%$ for all spectral bands. In contrast Sp\#10, a marine deposit and the sample with the lowest fines $(2.44 \%)$, has the smallest spectral variability (standard deviation less than $5 \%$ ).

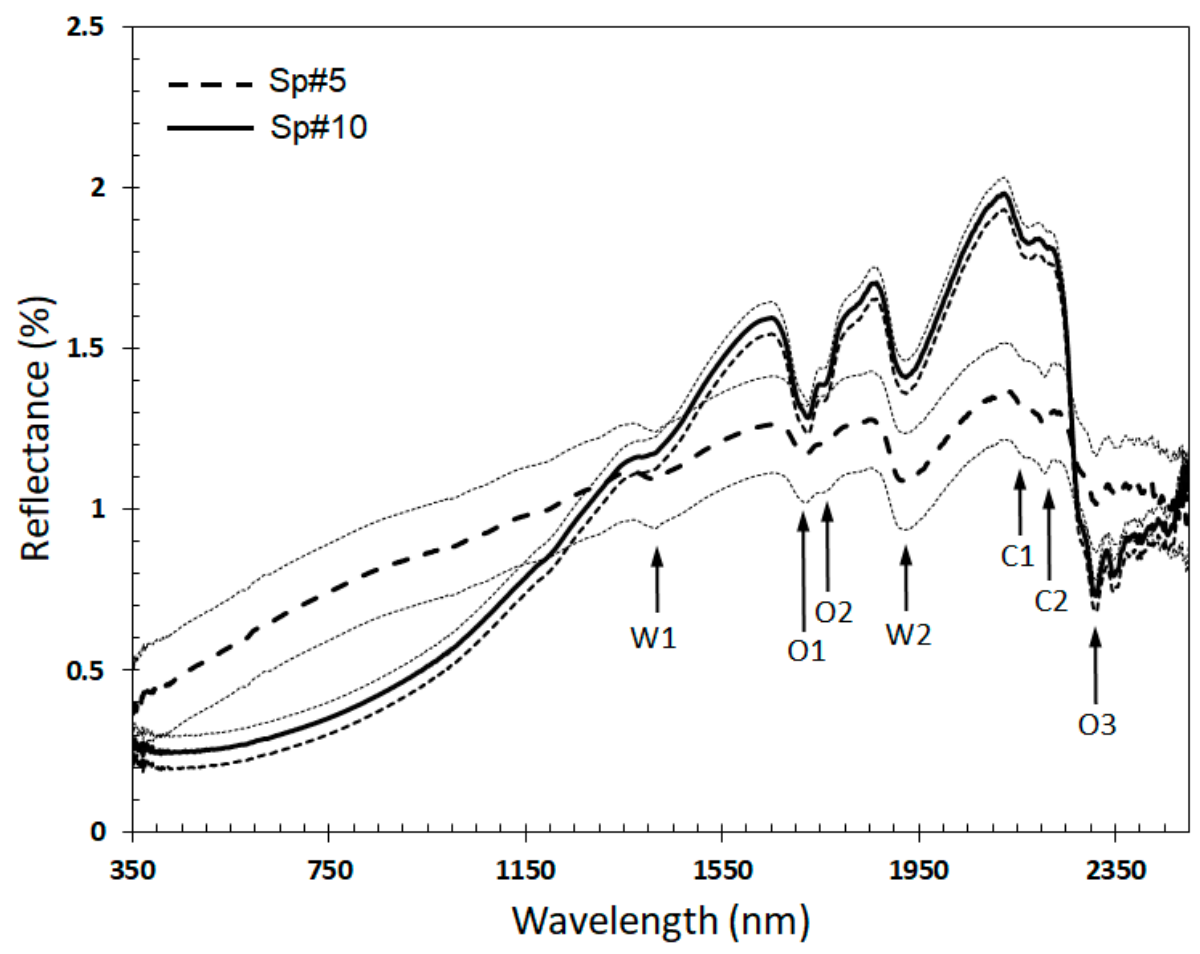

Figure 8. Average spectra for the 6 locations measured on two oil sand samples (Sp\#5, Sp\#10) and the standard deviation envelope displayed by grey lines about the mean spectra shown in black.

A number of recurring diagnostic spectral features were observed in the spectra of the samples (Figure 8). These features include water absorptions centered at 1.40 (W1) and $1.90 \mu \mathrm{m}$ (W2), bitumen features at $1.73(\mathrm{O} 1), 1.76(\mathrm{O} 2)$ and $2.31 \mu \mathrm{m}(\mathrm{O} 3)$, and clay features at $2.16(\mathrm{C} 1)$ and $2.20 \mu \mathrm{m}$ (C2). The strength of these features is controlled by the abundance of each component in the sample. For example, the three bitumen features $(\mathrm{O} 1, \mathrm{O} 2$, and $\mathrm{O} 3$ on Figure 8$)$ are more pronounced in the spectrum of Sp\#10 $(\mathrm{TBC}=14.20 \%)$ than in that of Sp\#5 $(\mathrm{TBC}=9.45 \%)$. In regard to the features attributable to clays, the types of clay present will influence the relative strength and detailed location of the two spectral features listed. These spectral characteristics can therefore be exploited to quantitatively characterize properties of ore using spectral measurements.

\subsection{Predictive Models Using Spectra of Ore}

\subsubsection{Prediction of Bitumen and Fines Content in Ore}

In a previous study [11], we determined the spectral features sensitive to the variation of bitumen content in ore and examined the correlation coefficient between the wavelet power at each scale and 
wavelength with the known TBC values of the modeling sample suite. Features with highest correlation with TBC were used during the development of a TBC prediction model. Here we make use of this published TBC model [11] and report unpublished models that predict the sample percentage fines content for particles smaller than 44 and $3.9 \mu \mathrm{m}$ (pp44 and pp3.9). For consistency, we also examined the predictions provided by these three models for the ten samples used for the flotation experiments.

To generate a predictive model of pp44 and pp3.9, multiple regression analysis was conducted to model the relationship between pp44, pp3.9, and the wavelet power of different features. The best model to predict pp44 (Equation (1)) involves five features while the model to predict pp3.9 (Equation (2)) involves six features. The root mean square (RMS) error for the pp44 model is 2.07 for the modeling suite and 1.77 for the validation suite. The RMS error for the pp3.9 model is 7.35 for the modeling suite and 6.09 for the validation suite. Figure 9 compares predicted and observed values of TBC, pp44, and pp3.9 for both sample suites and reveals that the total bitumen content (TBC) and \%fines (pp44, pp3.9) estimated for the ten samples (squares on Figure 9) compare well with laboratory determined values, with the ten samples falling within the predictive error of the model determined from the larger suite of modeling and validation samples (circles in Figure 9). This applies to samples regardless of their froth color. One sample (Sp\#3 brown froth) forms an exception and is an outlier producing lower than expected pp3.9 values (Figure 9c).

$$
\begin{gathered}
\text { Predicted PP44 } 4^{V N I R}=33.81-948.61 \times \text { Index } 1+375.32 \times \text { Index } 2-1101.48 \times{ }_{2.199 u m}^{3} W P \\
\text { Predicted PP3.9 } 9^{V N I R}=7.61+219.88 \times \text { Index } 3-549.71 \times \text { Index } 1+192.19 \times \text { Index } 2-277.86 \times{ }_{2.199 u m}^{3} \text { WP }
\end{gathered}
$$

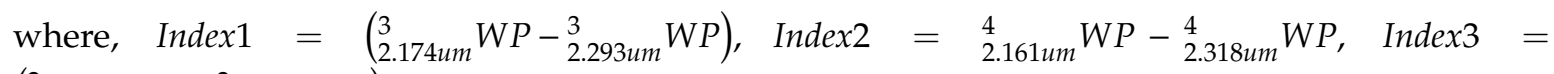
$\left({ }_{2.199 u m}^{2} W P-{ }_{2.299 u m} W P\right)$, and, ${ }_{\lambda}^{s} W P$ represents the wavelet power at scale $s$ at the wavelength $\lambda$.

\subsubsection{Prediction of Froth Color}

A correlation scaleogram was generated relating the spectral data and the froth color ID ( 0 for dark froth and 1 for brown froth). A uniform threshold of 0.75 was applied to the correlation coefficient values highlighting 15 spectral features listed in Table 3. These features encompass most of the bitumen, water, and clay features shown in spectra of Figure 8. Two additional features located at 0.502 and $0.749 \mu \mathrm{m}$ are highlighted. The reflectance at these two wavelengths is closely correlated to froth color and likely explains why experienced geologists can visually assess froth quality. The detected features were located at a variety of wavelet scales (1-7). Multiple regression analysis was conducted to model the relationship between froth color ID and the wavelet power of different features. Models with only three features were explored given the small size of the sample population (e.g., 10 spectra). The best three variable models (Equation (3)) involve water (W2), clay (C2), and bitumen (O1) features.

$$
\text { Predicted ID } D^{V N I R}=1.47+782.77 \times{ }_{1.976 u m}^{4} W P-78.15 \times{ }_{2.214 u m}^{2} W P-1524.09 \times{ }_{1.646 u m}^{3} W P
$$

In the model, ${ }_{\lambda}^{s} W P$ represents the wavelet power at scale $s$ at the wavelength $\lambda$ and the predicted ID for each sample is a real number that should approximate 0.0 (for samples with black froth) and 1.0 (for samples with brown froth). Cross validation indicates that the RMS (root mean square) error for the model is 0.08 . When the predicted color ID was compared to the observed color ID (Figure 10), the samples were well clustered by froth color with a maximum error of only \pm 0.2 , which means that if the predicted color ID was rounded to the nearest integer ( 0 or 1$)$, the samples would be classified into two classes predefined by froth color without error. Based on results from only 10 samples, the model performs well. 

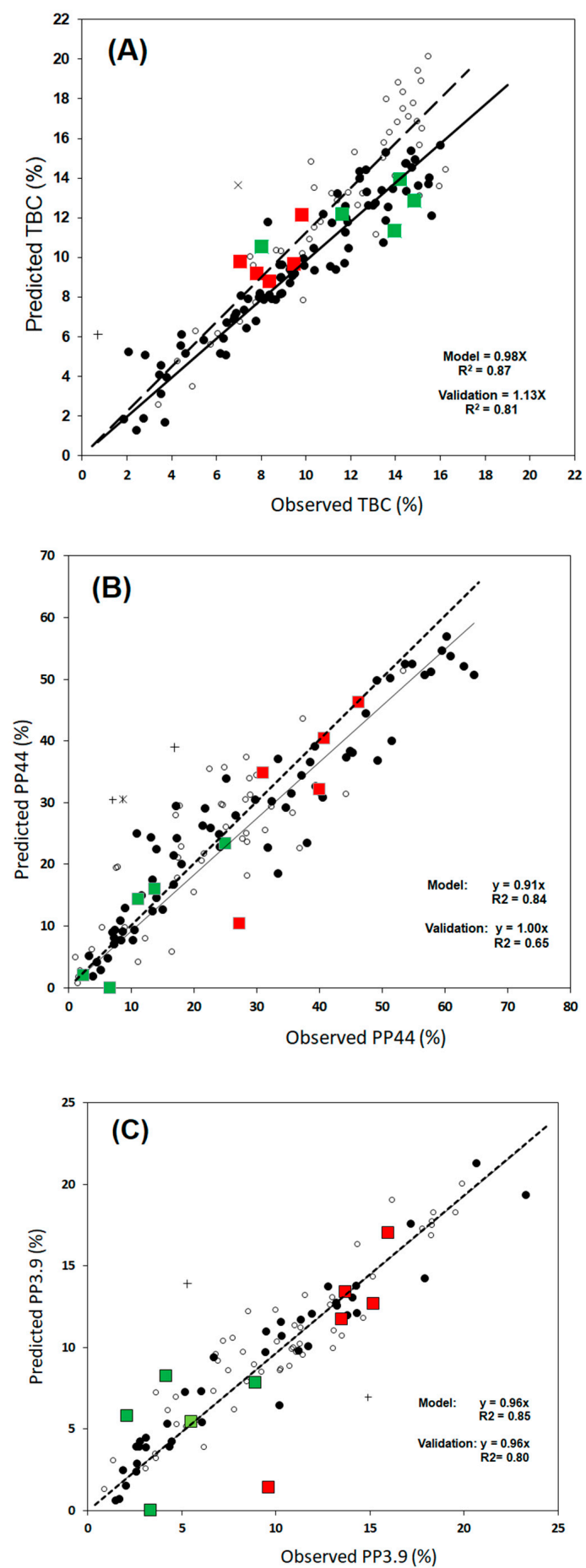

Figure 9. Comparison of spectrally derived and experimentally measured variables for (A) total bitumen content, (B) \% particle passing at $44 \mu \mathrm{m}$, and (C) \% particle passing at $3.9 \mu \mathrm{m}$. Filled and open circles represent the modeling and validation suite, respectively. + (modeling) and $\mathrm{x}$ (validation) mark the position of outliers (root mean square (RMS) error beyond $5 \%$ or $95 \%$ population). Solid and dashed line are best fits for the modeling and validation data, respectively. The ten samples used for the flotation experiment are shown as red and green squares for brown and dark froths, respectively. 
Table 3. List of wavelet spectral features best correlated to froth color, solid/bitumen, and processability.

\begin{tabular}{|c|c|c|c|c|c|c|}
\hline \multirow{2}{*}{ Wavelength $(\mu \mathrm{m})$} & \multirow{2}{*}{ Correlation Coefficient } & \multirow{2}{*}{ Scale } & \multirow{2}{*}{ Description } & \multicolumn{3}{|c|}{ Detected(-)/Used(X) } \\
\hline & & & & Color & SBR & Proc. \\
\hline 0.502 & 0.875 & 2 & In visible range & - & & \\
\hline 0.749 & 0.881 & 2 & In visible range & - & & \\
\hline 1.629 & 0.929 & 2 & Bitumen (O1) left shoulder & & - & \\
\hline 1.646 & 0.869 & 3 & Bitumen (O1) left shoulder & $x$ & & \\
\hline 1.697 & 0.830 & 2 & Bitumen (O1) & - & & \\
\hline 1.744 & 0.838 & 1 & Bitumen $(\mathrm{O} 1 / \mathrm{O} 2)$ & - & & \\
\hline 1.758 & 0.771 & 4 & Bitumen $(\mathrm{O} 2)$ & - & & \\
\hline 1.766 & 0.799 & 2 & Bitumen $(\mathrm{O} 2)$ & - & & \\
\hline 1.781 & 0.928 & 2 & Bitumen $(\mathrm{O} 2)$ right shoulder & - & & \\
\hline 1.864 & 0.854 & 7 & Water (W2) & - & & \\
\hline 1.976 & 0.839 & 4 & Water (W2) & $x$ & & \\
\hline 2.020 & 0.883 & 2 & Water (W2) & & & - \\
\hline 2.040 & 0.898 & 3 & Water (W2) & & & $x$ \\
\hline 2.040 & 0.911 & 2 & Water (W2) & & - & \\
\hline 2.077 & 0.838 & 2 & Water (W2) & & & - \\
\hline 2.077 & 0.881 & 2 & Water (W2) & & - & \\
\hline 2.120 & 0.750 & 3 & Clay(C1) left shoulder & - & & \\
\hline 2.143 & 0.821 & 4 & Clay (C1) & & & - \\
\hline 2.145 & 0.905 & 3 & Clay (C1) & & - & \\
\hline 2.163 & 0.821 & 1 & Clay (C1) & - & & \\
\hline 2.163 & 0.870 & 2 & Clay (C1) & & - & \\
\hline 2.175 & 0.948 & 6 & Clay (C1) & & - & \\
\hline 2.182 & 0.825 & 3 & Clay (C1) & & & $x$ \\
\hline 2.182 & 0.909 & 4 & Clay (C1) & & - & \\
\hline 2.187 & 0.957 & 5 & Clay (C1) & & $x$ & \\
\hline 2.189 & 0.814 & 5 & Clay (C1/C2) & & & - \\
\hline 2.210 & 0.890 & 1 & Clay (C2) & & & - \\
\hline 2.213 & 0.958 & 3 & Clay (C2) & & - & \\
\hline 2.214 & 0.793 & 2 & Clay (C2) & $x$ & & \\
\hline 2.218 & 0.909 & 1 & Clay $(\mathrm{C} 2)$ right inflection & & & $x$ \\
\hline 2.219 & 0.961 & 1 & Clay (C2) right inflection & & $x$ & \\
\hline 2.236 & 0.827 & 7 & Clay (C2) right shoulder & - & & \\
\hline 2.247 & 0.803 & 2 & Bitumen (O3) left shoulder & & & - \\
\hline 2.259 & 0.805 & 6 & Bitumen (O3) left inflection & & & - \\
\hline 2.259 & 0.897 & 5 & Bitumen (O3) left inflection & & - & \\
\hline 2.294 & 0.812 & 4 & Bitumen (O3) & & & - \\
\hline 2.294 & 0.882 & 4 & Bitumen (O3) & & - & \\
\hline 2.395 & 0.805 & 7 & Bitumen (O3) & - & & \\
\hline 2.404 & 0.975 & 5 & Bitumen (O3) & & $x$ & \\
\hline 2.409 & 0.853 & 4 & Bitumen (O3) & & & - \\
\hline
\end{tabular}

Detected(-) refers to features of high correlation, $\operatorname{Used}(\mathrm{X})$ refers to used in the model. Color = froth color, $\mathrm{SBR}=$ solids/bitumen, Proc. $=$ processability . 


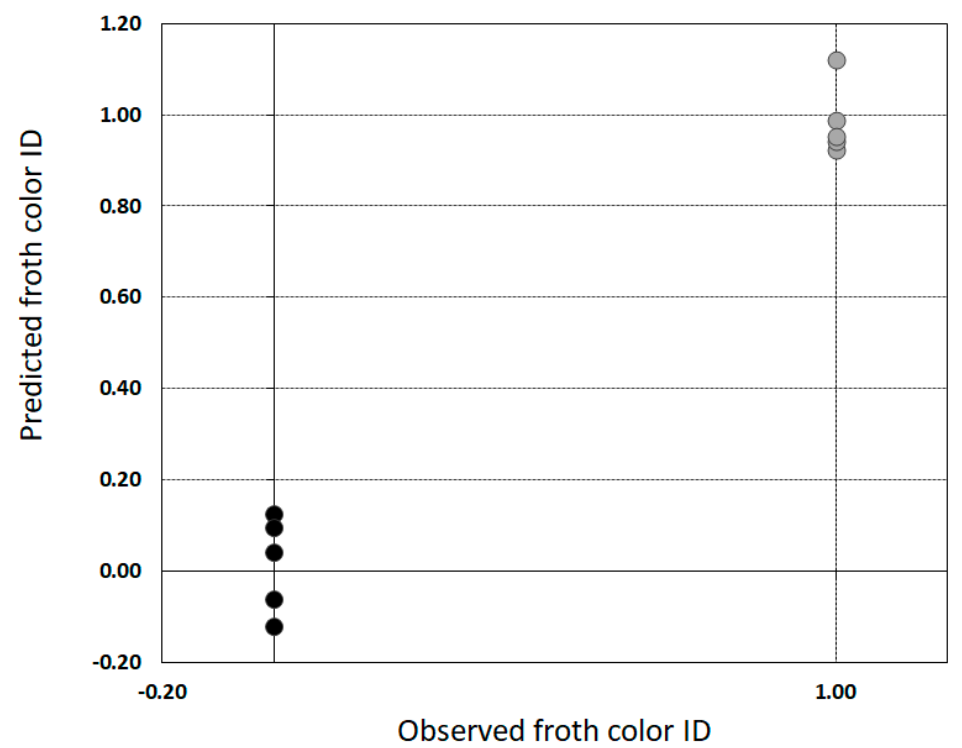

Figure 10. Scatter plot of observed and predicted froth color ID. Black circles = samples with dark froth; grey circles $=$ samples with brown froth.

\subsubsection{Prediction of Solids/Bitumen in Froth}

Solids in froth are typically dominated by fine and ultrafine particles. The solids need to be removed prior to the bitumen upgrading process. The solids and water content in froth also has implications for piping the froth to upgrading facilities as they tend to clog the transportation pipes over time. The solids affect the color and quality of froth, and offer a qualitative assessment of froth quality. Thus, prediction of the solids to bitumen Ratio (SBR) in froth before ore enters the separation vessels is important.

A correlation scaleogram was generated relating the ore spectra data and the SBR of related froth. A uniform threshold of 0.80 was applied to the correlation coefficient values highlighting 13 spectral features (Table 3) related to water, clay, and bitumen. The best three-variable model (Equation (4)) involved one bitumen (O3) and two clay features (C1 and $\mathrm{C} 2)$.

$$
\text { Predicted } S B R^{V N I R}=1.73+107.04 \times{ }_{2.219 u m}^{1} W P+42.27 \times{ }_{2.404 u m}^{5} W P-9.43 \times{ }_{2.187 u m}^{5} W P
$$

When the observed SBR value is compared to the predicted value for the ten samples (Figure 11), a best fit line through the data displays a slope of one, which indicates that the prediction model is unbiased. Cross validation indicates that the RMS error for the model is 0.33 .

\subsubsection{Prediction of Processability}

The processability of the ten samples ranged from 0.28 to 0.90 (Table 2). A correlation scaleogram was generated relating the spectral data and the processability. A uniform threshold of 0.8 was applied to the correlation coefficient values, highlighting twelve spectral features listed in Table 3. These features include water, clay, and bitumen features, which suggests that processability is related to the fraction of these components in the ore. The best three-variable model (Equation (5)) involved a water feature (W2) and two clay features (C1 and C2).

$$
\text { Predicted Processability }^{\text {VNIR }}=0.65+202.42 \times{ }_{2.04 u m}^{3} W P-156.11 \times{ }_{2.218 u m}^{1} W P-37.64 \times{ }_{2.182 u m}^{3} W P
$$

When the observed processability is compared to the predicted value for the ten samples (Figure 12), cross validation indicates that the RMS error of the model is 0.03 in absolute processability value, 
or $5.53 \%$ relative to the observed value. A best fit line through the data displays a slope of one, indicating that the prediction model is unbiased.

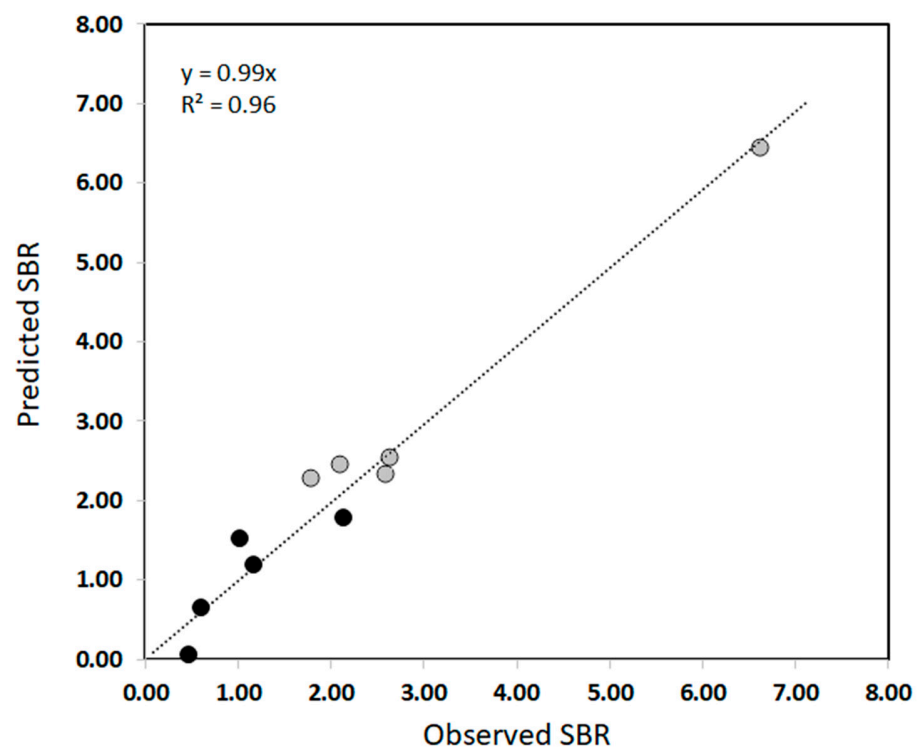

Figure 11. Scatter plot of observed and predicted solids/bitumen (SBR). Black circles = samples with dark froth; grey circles = samples with brown froth.

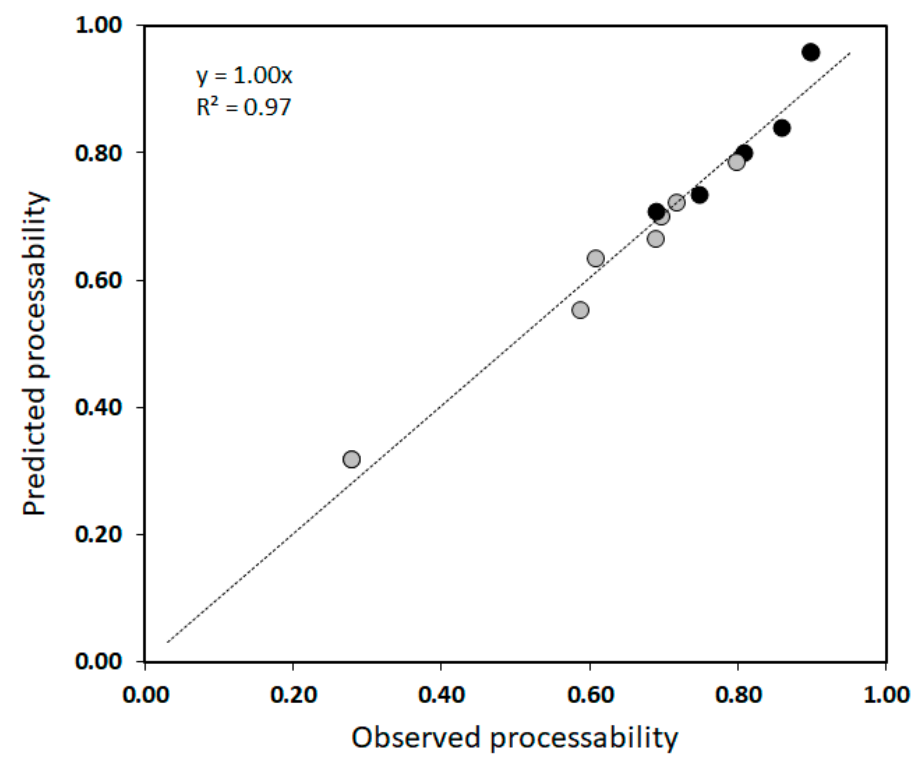

Figure 12. Scatter plot of observed and predicted processability. Black circles = samples with dark froth; grey circles = samples with brown froth.

\section{Discussion}

\subsection{Predicting Froth Characteristics and Ore Processability}

Froth color is a subjective qualitative descriptor of froth quality which we attempted to predict given its use in industry. In this case, froth color is reduced to two classes, namely dark (better quality) and brown (worst). The predictive model based on ten samples and spectral features of three primary froth constituents (bitumen, water, clays) has a high classification accuracy. It thus appears feasible that the model could be used in a plant as a descriptor of froth quality. 
We note that two samples of similar ore characteristics (TBC, pp44) but from different depositional environments yielded froths of different colors. Sp\#8 (low-grade ore fluvial sediment) with only $8.05 \%$ TBC and moderate fines content (pp44 $=24.98 \%$ ) is not a high-grade ore but resulted in a dark froth. Sp\#3 (high-grade bedded marine sediment) has higher TBC (9.82\%) and fines contents (pp44=27.30\%) and resulted in a brown froth. These results suggest that in some cases froth color may be related not only to the pp44 fines content in the ore but to the nature of the finer size fractions in the ore and also to the type of clays and their partitioning in varying size fractions in froth. Further insights are provided in our companion paper where fines content in froth is documented. We also note that the froth color of Sp\#8 was dark and it was assigned a class ID of 0 . If it is assigned to the class of brown froth, then all dark froths would result from the four samples with lowest fines and highest bitumen content and a clear distinction on the basis of these ore characteristics would be observed for both froth color classes. Such a change in the analysis, which is minor, reflects the subjective nature of froth color visual determination.

This study also corroborated the expected association of darker froths (better quality) with ores of higher TBC and lower solids content. This implies that models that can predict the TBC, pp44, and pp3.9 of ores could be used to provide a first order measure of froth quality.

Models predicting the solids/bitumen of froth and the processability of ore as opposed to the color of froth are inherently more valuable for potential process control given that they predict a continuous variable and are based on quantitative metrics. Both models are unbiased and display a high $\mathrm{r}^{2}(>0.97)$ despite being based on few variables $(<4)$. It is worth noting that each model is based on distinct spectral phenomena, the solids/bitumen model resting on information related to bitumen and clay while the processability model rests on information related to water and clay.

\subsection{Relevance to Process Control}

This study has identified a suite of predictive capabilities based on spectral measurements of ore that could potentially be used for process control. Spectral observations collected on ore upstream of the separation vessels could be used to provide a prediction of froth quality before blended ore enters the plant. These predictions could be combined to observations of froth quality in the flotation cell, as discussed in our companion paper, to establish a feedback control of the flotation process or simply to identify when ore of poorer quality is about to impact the performance of the flotation process. These models could also potentially be used to monitor and control the performance of the blending process as another means to control the performance of the flotation process.

\subsection{Further Studies}

Conducting flotation experiments is a logistically complex and time-consuming process, thus the relatively small size in the number of experiments conducted for this study. However, the results have demonstrated the feasibility of predicting froth quality and ore processability based on reflectance data, the next step being to raise the number of observations either via more laboratory flotation experiments or the use of a small-scale separation plant. In our companion paper, we report on further flotation results incorporating further information on the fines content of ore as well as documenting the fines content in related froth. These data are used to provide insights into samples presenting similar processabilities but differing froth characteristics.

\section{Conclusions}

This study corroborated the expected association of darker froths (better quality) with ores of higher TBC and lower solids content. From spectral observations of ore, models can predict the TBC, pp44, and pp3.9 of ore but the models with highest $\mathrm{r}^{2}$ (>0.96) predict the solids/bitumen of froth and the processability of ore. These could provide a first order measure of expected froth quality prior to ore entering the flotation cell. Each of these two models is based on distinct spectral phenomena, the solids/bitumen model resting on information related to bitumen and clay while 
the processability model rests on information related to water and clay. They may thus provide complementary information for predicting flotation performance based on spectra of ore.

The predictive capabilities defined in this study based on spectral measurements of ore could potentially be used for process control. Spectral observations collected on ore upstream of the separation vessels could predict froth quality for an ore blend before the ore enters the plant. These models could also potentially be used to monitor and control the performance of the blending process and the effect of separation cell process additives as another means to control the performance of the flotation process.

\section{Patents}

US Patent 9376627. Rivard, B.; Feng, J.; Lipsett, M. Hyperspectral imaging for ore froth characterization.

Canadian Patent 2780169. Rivard, B.; Feng, J.; Lipsett, M. Hyperspectral imaging for ore froth characterization.

Author Contributions: Conceptualization, B.R. and M.L.; Data capture, J.F., M.L., D.R., V.B.; Data analysis and modeling, J.F.; Writing-Review and Editing, B.R., J.F., M.L.; Funding acquisition, B.R. and M.L. All authors have read and agreed to the published version of the manuscript.

Funding: This research was funded by the Center for Oil Sands Innovation at the University of Alberta, grant number 2011-06.

Acknowledgments: This research was made possible by an infrastructure grant from the Canadian Foundation for Innovation under the John R. Evans Leaders Fund - Funding for research infrastructure, project 22222.

Conflicts of Interest: The authors declare no conflict of interest.

\section{References}

1. Bichard, J.A. Oil Sand Composition and behavior Research. In AOSTRA Technical Publication Series 4; Alberta Oil Sands Technology and Research Authority: Edmonton, AB, Canada, 1987; Chapter 1; pp. 6-62.

2. Masliyah, J.; Zhou, Z.J.; Xu, Z.; Czarnecki, J.; Hamza, H. Understanding water-based bitumen extraction from Athabasca oil sands. Can. J. Chem. Eng. 2004, 82, 628-654. [CrossRef]

3. Harjai, S.K.; Flury, C.; Masliyah, J.; Drelich, J.; Xu, Z. Robust aqueous-nonaqueous hybrid process for bitumen extraction from mineable Athabasca oil sands. Energy Fuels 2012, 26, 2920-2927. [CrossRef]

4. Schramm, L.L.; Stasiuk, E.N.; MacKinnon, M. Surfactants in Athabasca oil sands slurry conditioning, floatation recovery, and tailings processes. In Surfactants: Fundamentals and Applications in the Petroleum Industry; Schramm, L.L., Ed.; Cambridge University Press: Cambridge, UK, 2000.

5. Fong, N.; Ng, S.; Chung, K.H.; Tu, Y.; Li, Z.; Sparks, B.D.; Kotlyar, L.S. Bitumen recovery from model systems using a warm slurry extraction process: Effects of oil sands components and process water chemistry. Fuel 2004, 83, 1865-1880. [CrossRef]

6. Wiley \& Sons. Wiley Critical Content_Petroleum Technology; Wiley- Interscience: Hoboken, NJ, USA, 2007; Volume 1, pp. 222-240.

7. Hepler, L.G.; His, C. AOSTRA Technical Handbook on Oil Sands, Bitumen's, and Heavy Oils. In AOSTRA Technical Publication Series 6; Alberta Oil Sands Technology and Research Authority: Edmonton, AB, Canada, 1989; Chapter 2; pp. 14-20.

8. Thompson, G.R. Method and Apparatus for On-Line Monitoring of Bitumen Content in Tar Sand. Canadian Patent 1139702, 18 January 1984.

9. Shaw, R.; Kratochil, B. Near infrared diffuse reflectance analysis of Athabasca oil sand. Anal. Chem. 1990, 62, 167-174. [CrossRef]

10. Cloutis, E.A.; Gaffey, M.; Mosiow, T. Characterization of minerals in oil sands by reflectance spectroscopy. Fuel 1995, 74, 874-879. [CrossRef]

11. Lyder, D.; Feng, J.; Rivard, B.; Gallie, A.; Cloutis, E. Remote bitumen content estimation of Athabasca oil sand from hyperspectral infrared reflectance spectra using Gaussian singlets and derivative of Gaussian wavelets. Fuel 2010, 89, 760-767. [CrossRef]

12. Rivard, B.; Lyder, D.; Feng, J.; Gallie, A.; Cloutis, E. Bitumen content estimation of Athabasca oil sand from broad band infrared reflectance spectra. Can. J. Chem. Eng. 2010, 88, 830-838. [CrossRef] 
13. Shchepetkina, A.; Speta, M.; Gingras, M.; Rivard, B.; Pemberton, G. Hyperspectral imaging as an aid for facies analysis in massive-appearing sediments: A demonstrative case study for the middle McMurray formation. Bull. Can. Pet. Geol. 2017, 65, 262-278. [CrossRef]

14. Speta, M.; Rivard, B.; Feng, J.; Lipsett, M.; Gingras, M. Hyperspectral imaging for the determination of bitumen content in Athabasca oil sands core samples. AAPG Bull. 2015, 99, 1245-1259. [CrossRef]

15. Speta, M.; Gingras, M.; Rivard, B. Shortwave infrared hyperspectral imaging: A novel method for enhancing the visibility of sedimentary and biogenic features in oil-saturated core. J. Sediment. Res. 2016, 86, 830-842. [CrossRef]

16. Speta, M.; Rivard, B.; Feng, J. Shortwave infrared $(1.0-2.5 \mu \mathrm{m})$ hyperspectral imaging of the Athabasca West Grand Rapids Formation oil sands. AAPG Bull. 2018, 102, 1671-1683. [CrossRef]

17. Asadzadeh, A.; de Souza Filho, C.R.; Nanni, M.R.; Batezelli, A. Multi-scale mapping of oil-sands in Anhembi (Brazil) using imaging spectroscopy. Int. J. Appl. Earth Obs. Geoinf. 2019, 82, 101894. [CrossRef]

18. Bulmer, J.T.; Starr, J. Syncrude Analytical Methods for Oil Sand and Bitumen Processing in Methods 2.9 and 2.10: Classical and Syncrude Methods for the Determination of Bitumen. In Water and Solids Content of Froth; AOSTRA: Edmonton, AB, Canada, 1979.

19. Zhou, Z.; Xu, Z.; Masliyah, J. Effect of Natural Surfactants Released from Athabasca Oil Sands on Air Holdup in a Water Column. Can. J. Chem. Eng. 2008, 78, 617-624. [CrossRef]

20. Jia, B. Distribution of Oil Sands Formation Water in Bitumen Froth. Master's Thesis, University of Alberta, Edmonton, AB, Canada, 2010.

21. Bruce, L.M.; Li, J. Wavelets for computationally efficient hyperspectral derivative analysis. IEEE Trans. Geosci. Remote. Sens. 2001, 39, 1540-1546. [CrossRef]

22. Bruce, L.M.; Morgan, C.; Larsen, S. Automated detection of subpixel targets with continuous and discrete wavelet transforms. IEEE Trans. Geosci. Remote. Sens. 2001, 39, 2217-2226. [CrossRef]

23. Bruce, L.M.; Li, J.; Huang, Y. Automated detection of subpixel hyperspectral targets with adaptive multichannel discrete wavelet transform. IEEE Trans. Geosci. Remote. Sens. 2002, 40, 977-979. [CrossRef]

24. Bruce, L.M.; Mathur, A.; Byrd, J.D. Denoising and wavelet-based feature extraction of MODIS multi-temporal vegetation signatures. GISci. Remote. Sens. 2006, 43, 170-180. [CrossRef]

25. Li, J.; Bruce, L.M. Wavelet-based feature extraction for improved endmember abundance estimation in linear unmixing of hyperspectral signals. IEEE Trans. Geosci. Remote. Sens. 2004, 42, 644-649. [CrossRef]

26. Blackburn, G.A. Wavelet decomposition of hyperspectral data: A novel approach to quantifying pigment concentrations in vegetation. Int. J. Remote. Sens. 2007, 28, 2831-2855. [CrossRef]

27. Blackburn, G.A.; Ferwerda, J.G. Retrieval of chlorophyll concentration from leaf reflectance spectra using wavelet analysis. Remote. Sens. Environ. 2008, 112, 1614-1632. [CrossRef]

28. Rivard, B.; Feng, J.; Gallie, A.; Sanchez-Azofeifa, A. Continuous wavelets for the improved use of spectral libraries and hyperspectral data. Remote. Sens. Environ. 2008, 112, 2850-2862. [CrossRef]

29. Feng, J.; Rivard, B.; Rogge, D.; Sanchez-Azofeifa, A. The longwave infrared (3-14 $\mu \mathrm{m})$ spectral properties of rock encrusting lichens based on laboratory spectra and airborne SEBASS imagery. Remote. Sens. Environ. 2013, 131, 173-181. [CrossRef]

Publisher's Note: MDPI stays neutral with regard to jurisdictional claims in published maps and institutional affiliations.

(C) 2020 by the authors. Licensee MDPI, Basel, Switzerland. This article is an open access article distributed under the terms and conditions of the Creative Commons Attribution (CC BY) license (http://creativecommons.org/licenses/by/4.0/). 